\title{
On the Administration of Colleges and Universities with the Green Development Concept
}

\author{
Leifeng Wang ${ }^{1}$ and Weiwei Liu ${ }^{2}$ \\ (Jingdezhen Ceramic University, Jingdezhen, Jiangxi 333403)
}

\begin{abstract}
To guide the administration of colleges and universities with the green development concept has not only important theoretical significance but also important practical value. In the view of ecological concept, review administration of colleges and universities, analyze problems in the administration of colleges and universities so as to reform administration of colleges and universities that are not suitable for the concept of green development and establish administration of colleges and universities under the guidance of green development concept.
\end{abstract}

Keywords: Green development concept; Administration at colleges and universities; Work; Reform

\section{试论绿色发展理念下的高校行政管理工作}

\author{
王䂞峰 ${ }^{1}$ 刘伟伟 $^{2}$ \\ (景德镇陶瓷大学, 江西景德镇 333000)
}

摘要: 用绿色发展理念指导高校行政管理工作不仅具有重要的理论意义, 还带有重要的现实价值。在生态理念的视域下, 审视高校行政管理工作, 是对高校管理工作存在的问题进行分析, 从而改革不适应绿色发展理念的高校行政管理工作, 进而 建成绿色发展理念下的高校行政管理工作。

关键词: 绿色发展理念; 高校行政管理; 工作; 改革

中图分类号: D523 文摘标识码: A

引言

高校行政管理工作担负着高校的正常运转, 它依托行政机关与行政管理制度, 对学校各项工作展开有 目的性的引导, 建设一个服务师生与社会的高质量服务体系 ${ }^{[1]}$ 用绿色发展理念来指导高校行政管理工作至 关重要, 使高校能适应社会发展、高校本身发展和满足人民需要的要求, 有利于建成绿色发展理念下的行 政管理工作。

\section{1. 用生态理论观照高校行政管理工作的意义}

高校行政管理工作是一个由绿色主体（高校各级行政管理人员）与绿色环境（政治、经济和文化等环 境）构成的完整的绿色系统, 它是一个特殊的专业管理工作。高校行政管理工作的成效如何, 直接关系到 高校各级管理人员与师生的身心健康发展, 成为全面发展的人。因而, 要在十八大届五中全会中的绿色发 展理念的指导下, 落实好并用绿色发展理念来构建高校行政管理工作。它具有重要的理论意义和实践价值。

从理论上来看, 高校行政管理人员要在思想上充实大学生的绿色理念, 对于大学生树立正确的人生观、 价值观与生命价值观具有重大意义。从实践上看, 高校管理工作按照绿色发展理念来管理高校, 有利于绿 色主体在校园与社会中用绿色发展理念来处理问题, 如安全问题, 节约问题与工作与学习问题等, 进而建 成美丽与和谐的校园。

\section{2. 绿色发展理念下高校行政管理工作的现状}

为了更好地了解当前绿色发展理念下的高校行政管理工作的现状, 进一步增强实效性, 笔者对江西部 
分高校, 如景德镇陶瓷大学、南昌大学、南昌航空大学、和江西科技师范大学的管理工作进行了实地调查。 本次调查共发出问卷 710 份, 收回试卷 680 份, 其中有效试卷 665 份, 有效回收率 93. 7\%。同时也访谈了 其高校个别管理人员的工作，为调查做了必要的补充。调查结果如下：

（一）当前高校行政管理工作总体上是值得肯定的, 各项管理工作开展得的较顺利。

1. 构建了相对完善的管理制度。在问及 “高校行政管理部门设置是否合理”的调查中，35\%的人认为 高校行政管理部门设置很合理, 33\%的人认为高校行政管理部门设置较合理。在调查 “高校行政管理部门 职能分配如何” 时, $40 \%$ 的人认为高校行政管理部门分配很好, $36 \%$ 的人认为高校行政管理部门。在访谈的 过程中, 笔者得知: 大多数的高校实行的是市场经济条件下的管理思路, 依托明确的管理制度, 对高校各 项管理工作展开有目的性的引导，促进了高校行政管理工作的顺利开展。

2. 加强了行政管理部门自身的建设。多数高校管理人员能够认识到高校行政管理培训的重要性, 积极 参与这一活动。在一项 “高校生态主体培训是否是一件重要的事” 的调查中, $75 \%$ 的人认为 “是很重要的 事, 有助于提高自身素质”, $20 \%$ 的人认为 “培训时间不如去做其它事情”。从数据分析上来看, 多数人已 意识到培训的重要性和紧迫性。事实证明, 高校管理人员愿意接受各种培训。数据显示: 有 $40 \%$ 的高校管 理人员通新媒体 (电视, 广播与网络等) 来接受培训, $32 \%$ 的高校管理人员还提出了有益于培训的具体内 容。

（二）在落实行政管理工作中, 与绿色发展理念的要求存在一定的距离, 对于办好人民满意的大学极 为不利。当问及高校人文精神如何” 时, $60 \%$ 的人说不清楚; 更有甚者, $51 \%$ 的人不知道 “生命价值观的意 义” 的概念, 选择 “了解一点” 的人为 $18 \%$ 。由此可见, 管理人员绿色理念知识匮乏, 需加强绿色发展理 念来指导高校行政管理工作。

\section{3. 当前高校行政管理工作存在问题的原因分析}

在国家大力推进生态文明建设战略的实施的前提下，高校未能充分重视绿色发展理念对高校管理工作 的的重要意义。因而, 从绿色发展理念的视域, 结合高校管理工作中存在的问题, 来具体分析产生问题的 原因, 以便更好地建设人民满意的大学。通过调查存在问题的数据分析, 笔者认为有如下几个方面的因素 问题原因分析如下:

（一）高校行政管理工作中存在着 “异化”，即高校行政管理权力超越学术权力。马克思说: “人同自 己的劳动产品、自己的生命活动、自己的类本质相异化的直接结果就是人同人相异化。” ${ }^{[2]}$ 高校管理人员本 应为高校教学与科研等方面提供服务工作, 协助老师处理各项繁琐的行政工作, 以便为学术活动提供便利 的环境。但在高校行政管理工作中, 时常会发生行政权力高于学术权力, 即 “高校学术术活动的顺利开展 必须依靠高校行政管理部门的支持, 教育教学资源的使用必须得到行政管理部门的首肯, 故高校学术科研 的创新活动受到严重的局限。而一项简单的学术科研活动就必须经历多种难关, 从申请、批准、再到实施 的过程往往要耗费难以想象的时间、物力与人力。” ${ }^{[3]}$ 因此, 高校行政管理工作成为学术的管理者和制约者。 正如马克思所言: “人生产的劳动产品已经作为一种异己的力量同他相对立。”

（二）高校行政管理的生态定位相对缺失，即高校行政管理过于集中，容易出现专权。因而在管理工 作作风上，官僚作风与等级制度依旧存在，与高校所倡导的高校民主发展与科学发展相违背。

第一，绿色发展理念未能深入管理人员之心。国外的生态思想可追溯至国外的生态社会主义思想，而 
我国的生态文明观始于在可持续发展思想与科学发展观, 国外的生态理论比我国要早, 如生态思想在国外 得到高校生态主体的重视，英国的高校生态主体负责管理高校的行为与意识。在我国，2008 年首次研讨建 设可持续发展校园问题, 结合生态理论知识, 提出要创新高校管理体系。生态问题得到高校生态主义的逐 步重视，但据笔者了解，还没有一本关于的绿色发展理念专著真正为高校行政管理工作服务。即绿色发展 理念没有大众化。

第二，高校管理人员没有切实把绿色发展理念用于高校行政管理工作之中。

虽说我国高校实行的是市场经济条件下的高校行政管理工作，容易受到计划经济体制时的高校行政管 理工作的影响, 沿用政府机关的逐级管理的方法, 易产生专权。这样会影响高校生态主体的工作作风, 很 难把绿色发展理念用于高校行政管理工作之中。此外, 高校管理人员意识形态呈现多元化趋势, 易滋生拜 金主义与个人主义等与绿色发展理念下高校管理工作不协调的思潮。当前, 特别是遇到经济效益与生态效 益矛盾时, 会出现追逐个人利益而无视生态效益。总之，高校行政管理工作中存在理论与行为上的脱节, 没有落实好绿色发展理念与高校行政管理工作的关系。

\section{4. 建成绿色发展理念下高校行政管理工作的思路}

建成绿色发展理念下高校行政管理工作,应根据国家对中国高等教育提出的新要求，在绿色发展理念 指导下, 注重从绿色发展理念来完善高校行政管理工作，做到以人为本，实施和谐的管理，为此，要完成 这一光荣的历史使命，需从以下几方面做起：

1. 坚持以人为本是建成绿色发展理念高校管理工作的思想基础。在制度建设上，要倡导去行政化，突出 学术和民主权力, 争取学术方面自由探讨、自由交流, 民主方面建成完善的校务公开机制、民主决策机制、 工作激励机制、人才聘任机制、干部约束机制和学生信息反馈机制等，使高校管理人员热心工作或者努力 学习, 共同践行绿色精神的高校制度文化。[4]

2. 在管理工作中要常体现高校管理人员的人文关怀。如，“对待考试作弊学生的监考管理, 部分高校的做 法是坚持禁止作弊的原则, 同时, 实施人性化的监考, 即发现作弊学生进行立即制止, 对 “作弊未遂” 的学 生进行事后的教育批评而取代了原有的记过处分。这种做法相较于原来的任其作弊, 等其造成作弊事实才 去批评处理, 将学生当作 “敌人” 的方法, 更多的加入了 “人文关怀” 管理的因素, 使处理问题具有人性化。” ${ }^{[5]}$ 同时, 要根据生态链原理, 整合优化教育资源配置, 改进教育手段, 降低教育成本, 提高办学效益; 要 倡导绿色生活方式, 提倡绿色消费, 既提高生活质量和健康水平, 又节约资源和减少污染。同时, 依法治 校, 做到管理规范, 服务工作井然有序; 做到 “换位思考”。孔子说过, 己所不欲, 勿施于人, 说的就是 通过换位思考，来体现人性化的管理。

3. 和谐的管理环境是要高校依法与民主治校, 在管理制度健全与管理科学规范的情况下。完善生态理论 特别是绿色发展理念下的高校行政管理工作环境，需加强硬件环境与软件环境的建设。

从硬件环境上来说，要从教务管理工作与学生管理工作等人手，降低管理工作的成本，提高管理工作 的效率。

在教务管理工作中，要在高校贯彻公平兼顾的原则, 强化对于管理人员在管理能力与工作态度等方面 的综合考核; 避免出现 “在部分高校, 人们普遍缺乏一种对科学与学术的敬畏之心和虔诚之心, 取而代之的 是对 “行政权威” 的羡慕, 乃至仰视、服从” ${ }^{[6]}$; 在学生工作上, 高校管理人员应尽可能开展绿色教育活动, 
如某高校在实践科学发展观的 “引领生态文明, 建设高水平林业大学” 的活动中, 积极发挥国家生态文明 教育基地的示范作用, 组织推进 “绿色校园与生态文明” 系列活动。 ${ }^{[7]}$ 结合本校的实际, 组织大学生参加 植树与环保宣传，鼓励教育大学生以生态思想内化为自己的品质，外化为自己的行为。

从软件环境来看，是建成绿色发展理念下高校行政管理工作的内在条件。高校管理人员树立绿色发展 理念, 在绿色发展理念与行为上, 将人的全面发展观教育与实现有机结合。绿色发展理念认为, 人的全面 发展包括人自身可持续发展能力的全面发展。而人的自身可持续发展能力离不开人与外部环境和谐共同发 展的能力, 人们提高身体健康素质的能力, 人们适应学习型社会的能力, 最重要的是人的创造性能力, 建 成人民满意的高校, 正是要以提高管理人员自身可持续发展能力为基础实施全面发展教育。因此人与自然、 人与人、人与社会关系的全面发展是人民满意的高校教育的主调; 和平、发展和健康教育是人民满意的高 校教育的主题; 管理人员自身可持续发展能力的培育提高是人民满意的高校教育的基础性目标。

\section{结语}

应将绿色发展理念纳入高校行政管理工作中，通过制定完善的环境管理制度，创设丰富的环境保护文 化氛围，全面提高高校管理人员的环境素养，开展有效的环境教育活动，使高校行政管理工作适应绿色发 展理念的要求。这不仅是高校全面贯彻行政管理工作的重要载体，也是管理好行政工作的重要方式。

\section{致谢}

基金项目:本文为 2016 年景德镇陶瓷大学校级教改项目 “马克思主义人学思想视角下的 “以生为本” 研究一以江西省部分高校为例” 的阶段性成果; 本文为 2016 年景德镇陶瓷大学研究生课题项目 “当代研 究生社会主义核心价值观培育研究”的阶段性成果。

基金项目：2016 年景德镇陶瓷大学校级教改项目 “马克思主义人学思想视角下的 ‘以生为本” 研究一 以江西省部分高校为例”、2016 年景德镇陶瓷大学研究生课题项目 “当代研究生社会主义核心价值观培育 研究”

\section{Acknowledgement}

Fund Project: 2016 Jindezhen Ceramic University's teaching reform project "A Study on the 'Student oriented' from the Perspective of Marxist Anthropology - A Case Study of Some Universities in Jiangxi Province from the Perspective of Marxist Anthropology"、2016 Jingdezhen Ceramic University graduate project " A Study on the College Students' Socialist Core Values "

\section{参考文献}

[1]杨进. 高校行政管理改革现状及策略 [J]．云南社会主义学院学报，2012，(5): 177 .

[2]马克思. 1844 年经济学哲学手稿[M]. 北京 : 人民出版社, 2008. 第 59 页.

[3]同 [1].

[4]廖福霖等著.生态文明经济研究 [M]。中国林业出版社，2010．第 344-345 页.

[5]曹运星、姚静. 基于服务理念的高校行政管理改革 $[J]$ 。中国科教创新导刊，2011，(22)：222.

[6]吴增基. 论我国高校的官本位倾向及其克服条件 [J]. 学术界，2006，（6）.

[7] 铁铮、赵海燕、田阳. 北京林业大学引领生态文明建设 [N].中国教育报, 2009-7-10.

[8] 廖福林等著.生态生产力导论-一 21 世纪财富的源泉和文明的希望 [M]。中国林业出版社, 2007.

\section{作者简介:}

王否峰, 博士, 景德镇陶瓷大学马克思主义学院讲师, 南昌大学博士后, 中国科学社会主义学会当代世界社会主义专业 委员会理事，福建省生态文明研究会理事。主要研究方向：马克思主义理论与实践以及应用对策研究;

刘伟伟, 硕士, 景德镇陶瓷大学研究生院学工部, 主要研究方向: 马克思主义理论及其思想政治教育。 


\section{References:}

[1] Yang Jin. Current Situation and Strategy of Administrative Reform in Colleges and Universities [J]. Journal of Yunnan Institute of Socialism, 2012, (5): 177.

[2] Marx. 1844 Economic Philosophy Manuscripts [M]. Beijing: People's Publishing House, 2008, p. 59.

[3] Same as [1].

[4] Liao Fulin, ET al.Study on ecological civilization economy [M]. China Forestry Publishing House, 2010, pp. 344-345.

[5] CAO Yun - xing, YAO Jing. Colleges and Universities' Administration Reform Based on Service Idea [J]. China Science and Education Innovation Guide, 2011, (22): 222.

[6] Wu Zengji.On the Prefectural Tendency of Chinese Universities and Its Overcoming Conditions [J]. Academic circles, 2006, (6).

[7] Tie Zheng, Zhao Haiyan, Tianyang. Hebei Forestry University Leading the Construction of Ecological Civilization [N]. China Education Journal, 2009-7-10.

[8] Liao Fulin, et al. Introduction to ecological productivity - the source of wealth in the 21st century and the hope of civilization [M]. China Forestry Press, 2007. 